\title{
INVESTIGATION OF DYNAMICS OF STUDENTS' SENSE OF LANGUAGE BY WORD ASSOCIATIVE EXPERIMENT METHOD
}

\author{
K. Aghababyan 1 \\ DOI: http://doi.org/10.15350/L_21/2/04
}

\begin{abstract}
The dynamics of students' sense of language (SL) is investigated by using of the word associative experiment method. Three-level scheme to develop of SL is designed: to get past the initial stage of the process as a student, to comprehend his own experience as a teacher and then, based on their own experience, to apply the acquired skills in a live teaching.
\end{abstract}

Keywords: sense of language, word associative experiment method, rating factor

Одной из основопомагающих путей совершенствования навыков вцадения родного языка является целенаправленное развитие "чувства языка" (ЧЯ) учащихся в процессе обучения. При этом под "чувством языка" понимается сложный психолингвистический процесс, сплетенный осознанно-логическими [1,2] и интуитивно-подсознательными [3, 4] элементами словестного восприятия мира, который обеспечивает формирование коммуникативной компетенции индивида и способствует ее развитию $[4,5]$.

Техномогия развития ЧЯ студентов в процессе их обучения можно представить следующей схемой (рис. 1): на первом этапе методом словестного ассоциативного эксперимента (САЭ) определяется начальный уровень ЧЯ студентов, после чего проводится одномесячное обучение по специально разработанным методикам и проверка знаний по тестам трехуровневой сложности. На четвертом этапе проводится повторное определение уровня ЧЯ, по результатам которого оценивается эффективность примененных методик обучения. Цикл 2-3-4-2 (рис. 1) можно повторить, исходя из желаемой величины достижения уровня ЧЯ обучаемых студентов. На пятом, шестом и седьмом этапах студенты педагогических вузов в процессе вузовского обучения и активой педагогической практки в школе приобретают умения и навыки применения методов оценки и методик развития ЧЯ школьников. Таким образом, предмагаемая технология развития ЧЯ студентов педагогических вузов разработана и применена по трехуровневой схеме: пройти начальную стадию процесса в качестве ученика, осмыслить все на собственном опыте и только затем, с учетом собственного опыта, применить приобретенные умения в живом педагогическом процессе.

${ }^{1}$ Karine Aghababyan, Senior Lecturer of Armenian state pedagogical University after Kh. Abovyan, Yerevan, Armenia. 


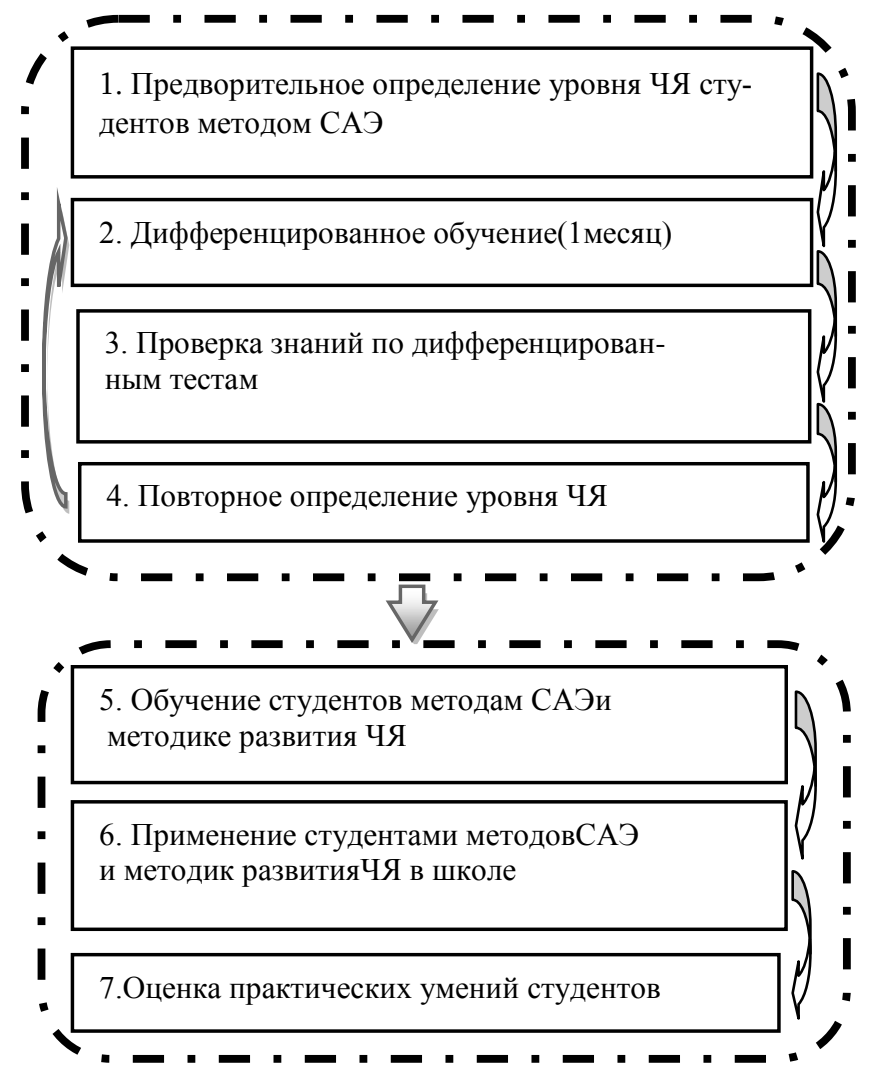

Рис. 1. Блок-схема технологии развития ЧЯ

В настоящей статье приведены результаты исследования динамики развития ЧЯ студентов третьего курса по специальности педагогика $u$ методика начального образования (1-4 этапы, рис. 1) и уровня их практических умений по результатам научно-педагогических исследований, проведенных ими в начальных классах во время педагогической практики (5-7 этапы, рис. 1).

Метод САЭ впервые быц детально проанализирован А. Тумбаем и К. Марбеем [6] и далее бым развит в работах Ю. Д. Апресяна [7], В.А. Вусфилда и сотр. [8], Ж. Диза [9]. В митературе разцичают нес-колько вариантов САЭ: когда в цепочке реакции на слово-стимул учитывается: 1) первое слово-реакция, 2) второе слово-реакция, 3) цепочка целиком [79]. Возможны также варианты многошаговых испытаний с применением самосогласо-ванных ассоциаций, когда САЭ проводится несколькими этапами: при этом словом-стимулом дия каждого последующего этапа служит слово-реакция предыдущего этапа $[7,8]$. По типу слов-стимулов разцичают также методы свободного (стимумом служит одно единственное слово) и направленного (в качестве стимула выступают словосочетания) САЭ. В наших исследованиях были использованы оба вида САЭ (рис. 2). Очевидно, процесс исследования ЧЯ носит опосредованный характер, так как ЧЯ проявляется на подсознательном или сознательном 
уровне при выявлении определенных предметных и/или моральноэтических отношений индивида с окружающим миром. В качестве таковых нами выбраны пять базовых составляющих гражданственности: историческая память, патриотизм, оптимизм, наиионализм, прогосударственность. Дия каждого из них выбраны по пять слов-стимулов, а шестое - выбрано произвольно, с целью минимизации возможности образования могических цепочек (рис. 2).

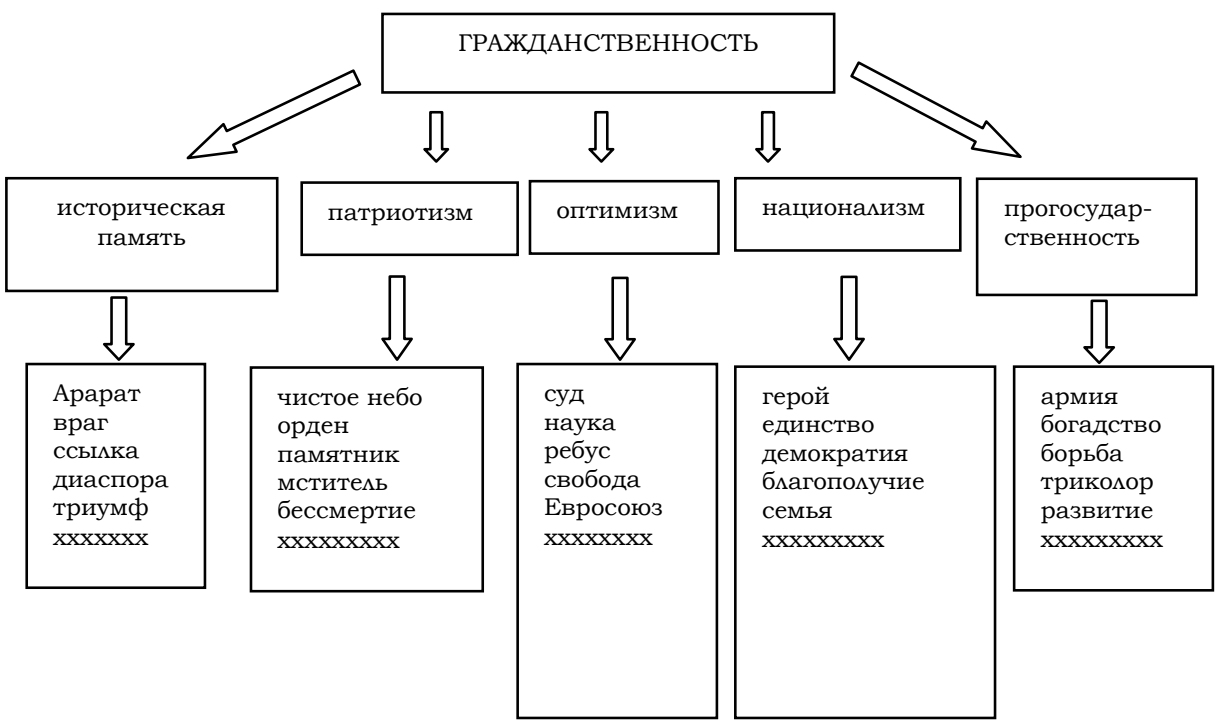

Рис. 2. Сцова-стимулы дмя САЭ

В эксперименте участвовали 27 студентов 3-го курса. Диительность САЭ составима 7 мин. Слова-стимулы диктовались в разупорядоченном порядке. При этом участники не были заранее ознакомлены с целями проведения эксперимента: им было предможено в течениие 5-7 сек на заранее приготовленных бланках перед номером продиктованного словастимула записать первое пришедшее на ум слово или словосочетание. При анализе результатов и количественной оценки учитывались первые слова-реакции. Оценка проводилась по четырехбалцьной системе: наивысшим 4 балмом оценивались наиболее глубинные слова-реакции (борьба - родина, победа); более поверхностные, типичные ответы получали 3 бамла (борьба - свобода, любовь); слова-реакции, являющиеся синонимами ими антонимами слов-стимулов, получали 2 балма (борьба битва, умиротворение); слова-реакции, являющиеся грамматической формой или простейшим смысловым продолжением слов-стимулов, помучали 1 бамл (борьба - борец, ринг). Суммарные бамлы каждого респондента приведены в таблице 1 . 
Таблица 1

Результаты первого и второго САЭ

\begin{tabular}{|c|c|c|c|c|c|c|c|c|c|c|c|c|c|}
\hline \multirow{2}{*}{ 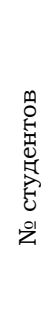 } & \multicolumn{2}{|c|}{$\begin{array}{c}\text { Первый } \\
\text { САЭ }\end{array}$} & \multicolumn{2}{|c|}{$\begin{array}{c}\text { Второй } \\
\text { САЭ }\end{array}$} & \multicolumn{2}{|c|}{$\begin{array}{l}\text { Изменение } \\
\text { уровня ЧЯ }\end{array}$} & \multirow{2}{*}{ 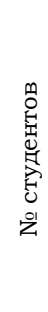 } & \multicolumn{2}{|c|}{$\begin{array}{c}\text { Первый } \\
\text { САЭ }\end{array}$} & \multicolumn{2}{|c|}{$\begin{array}{c}\text { Второй } \\
\text { САЭ }\end{array}$} & \multicolumn{2}{|c|}{$\begin{array}{l}\text { Изменение } \\
\text { уровня ЧЯ }\end{array}$} \\
\hline & 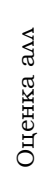 & 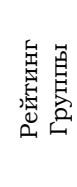 & 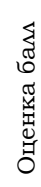 & 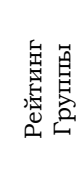 & 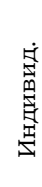 & 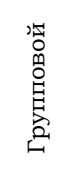 & & 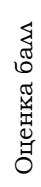 & 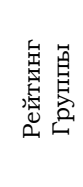 & 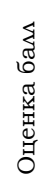 & 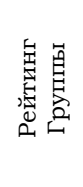 & 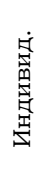 & 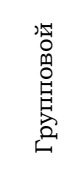 \\
\hline 1 & 20 & \multirow{6}{*}{$\begin{array}{c}0.24 \\
(0.32)\end{array}$} & 28 & \multirow{3}{*}{$\begin{array}{c}0.29 \\
(0.33)\end{array}$} & 8 & \multirow{6}{*}{0.05} & 14 & 55 & & 58 & & 3 & \multirow{4}{*}{0.04} \\
\hline 2 & 22 & & 33 & & 11 & & 15 & 55 & & 59 & & 4 & \\
\hline 3 & 32 & & 37 & & 5 & & 16 & 56 & & 59 & & 3 & \\
\hline 4 & 38 & & 42 & \multirow{7}{*}{$\begin{array}{c}0.43 \\
(0.45)\end{array}$} & 4 & & 17 & 58 & & 62 & & 4 & \\
\hline 5 & 39 & & 43 & & 4 & & 18 & 63 & \multirow{5}{*}{$\begin{array}{c}0.65 \\
(0.68)\end{array}$} & 67 & 0.64 & 4 & \multirow{5}{*}{-0.01} \\
\hline 6 & 39 & & 43 & & 4 & & 19 & 66 & & 71 & $(0.71)$ & 5 & \\
\hline 7 & 42 & \multirow{5}{*}{$\begin{array}{c}0.43 \\
(0.45)\end{array}$} & 45 & & 3 & \multirow{5}{*}{0} & 20 & 69 & & 74 & & 5 & \\
\hline 8 & 44 & & 47 & & 3 & & 21 & 70 & & 75 & \multirow{7}{*}{$\begin{array}{l}0.78 \\
(0.83)\end{array}$} & 6 & \\
\hline 9 & 44 & & 47 & & 3 & & 22 & 73 & & 76 & & 3 & \\
\hline 10 & 46 & & 49 & & 3 & & 23 & 77 & \multirow{5}{*}{$\begin{array}{c}0.76 \\
(0.81)\end{array}$} & 82 & & 5 & \multirow{5}{*}{0.02} \\
\hline 11 & 47 & & 52 & \multirow{4}{*}{$\begin{array}{c}0.56 \\
(0.57)\end{array}$} & 5 & & 24 & 78 & & 85 & & 7 & \\
\hline 12 & 51 & \multirow{3}{*}{$\begin{array}{c}0.52 \\
(0.55)\end{array}$} & 55 & & 4 & & 25 & 78 & & 85 & & 7 & \\
\hline & & & & & & & 26 & 82 & & 88 & & 6 & \\
\hline 13 & 53 & & 57 & & 4 & & 27 & 88 & & 92 & & 4 & \\
\hline
\end{tabular}

Далее по набранным балмам быми образованы группы: в первую группу вошии студенты, набравшие до 40; во вторую - от 41 до 50; в третью - от 51 до 60, в четвертую - от 61 до 75 и в пятую - более 75 балмов. (Отметим, что выбор интервалов набранных бамлов несколько произволен и может быть изменен в зависимости от конкретной ситуации. Важно мишь то, чтобы в одну и ту же группу были вовлечены студенты с близким уровнем ЧЯ и чтобы группа содержала не менее трех и не более семи членов.) Далее определялся рейтинг группы по формуле

$$
\delta=(M \xi-\sqrt{D \xi}) / 100,
$$

где $M \xi=\frac{1}{N} \sum_{i=1}^{N} x_{i} и D \xi=\frac{1}{N} \sum_{i=1}^{N} x_{i}^{2}-(M \xi)^{2}-$ соответственно, математическое ожидание и дисперсия случайной величины $\xi, x_{1}, x_{2}, \cdots x_{N}-$ оценки участников данной группы, N - число студентов в группе. Заметим, что максимальное значение рейтинга группы $\delta_{\max }=M \xi / 100$ достигается при нулевом значении дисперсии, т.е. при $D \xi=0$, (в этом предельном случае набранные балы каждого чмена группы равны). Очевидно, близость значения рейтинга группы к $\delta_{\max }$, обеспечивает степень достоверности информации об уровне ЧЯ каждого чмена данной группы. Именно по этой причине в одну и ту же группу следует вкАючать респондентов, получивших максимально близкие балмы.

В табл. 1 указаны группы респондентов после первого САЭ, приведе- 
ны рассчитанные и максимальные (в скобках) значения рейтингов групп.

Следует отметить, что одномесячные занятия проводимись совместно со всеми студентами по единой программе и методикам (сами студенты не уведомлялись об их принадлежности к той или иной группе). Однако, после месячных занятий проверка знаний по всем темам проводилась по заданиям трехуровневой степени сложности. Оценивание выполненных заданий также проводицось по особой методике: в этом процессе наряду с преподавателем участвовали как другие студенты (оценивание презентаций, эссе и т.п.), так и сам экзаменуемый (самооценка). Окончательная рейтинговая оценка формировалась умножением оценки задания той или иной степени сложности на рейтинговый показатель группы, в которую входиц студент, выполнивший данное задание.

После проведенных занятий и оценки заданий, с целью определения эффективности использованных методик обучения, был проведен повторный САЭ по тем же стимулам-словам, но продиктованным в иной последовательности. Результаты анализа второго САЭ: суммарные балы респендентов, реорганизованные группы, рассчитанные и максимальные значения рейтингов групп приведены в таблице 1. Видно, что все студенты получили более высокие балмы, что и привело к повышению рейтинга некоторых групп, приближая их к максимальному значению. С $е$ дует отметить, что, поскоцьку после второго САЭ происходит существенное перераспредемение студентов по группам, то, очевидно, что рейтинги некоторых групп могут понизиться. Например, рейтинг 4-ой группы, в состав которой вошии другие студенты, а прежние перешии в группы с более высоким рейтингом, понизился (табл. 1). Однако, в цюбом случае, максимальное значение рейтингов групп растет, что свидетельствует о росте уровня ЧЯ каждого отдельного респондента (табл. 1).

С целью подготовки студентов к педагогико-исследовательской деятельности (5-ый этап) были проведены трейнинги, по окончании которых они приобрели навыки и умения применения метода САЭ дмя опредемения уровня ЧЯ школьников. Были составлены необходимые учебные материалы для проведения педагогико-исследовательской работы в начальной школе (выбор слов-стимулов с учетом возрастных особенностей респондентов, составление дидактических материалов и заданий трехуровневой сложности в рамках учебных программ начальных классов и т.д.). Далее студенами-практикантами бымо проведено исследование динамики ЧЯ учащихся начальной школы. В качестве респондентов были выбраны ученики трех третьих классов: 15 учеников из 3а, 21 - из $3^{б}$ и 25 из 3г. В качестве объекта исследования были выбраны пять базовых составцяющих ценностной системы: родина, семья, природа, образование и искусство. На первом этапе методом САЭ бым опредемен начальный уровень ЧЯ и по описанной выше методике формированы группы дмя проведения групповой работы. Слова-стимулы приведены на рис.3. Отметим, что в одну и ту же группу вошии ученики с примерно равным уровнем ЧЯ, что, во-первых, обеспечило равные условия для каждого члена группы, во-вторых, минимизировало возможность использования учеником результатов со-товарища по группе, тем самым повышая его активность и, в третьих, как показал анализ полученных данных, обеспечимо непрерывное развитие ЧЯ каждого ученика. В каждом классе студенты провели три групповые работы по заранее составленным дифференцированным заданиям трехуровневой сложности в рамках школь- 
ной учебной программы. При этом в группах с рейтинговым коэффициентом до 0.5 применялись простые задания, в группах с рейтингом от 0.5 до 0.7 - задания средней сложности и в группах с рейтингом выше 0.7 задания повышенной сложности.

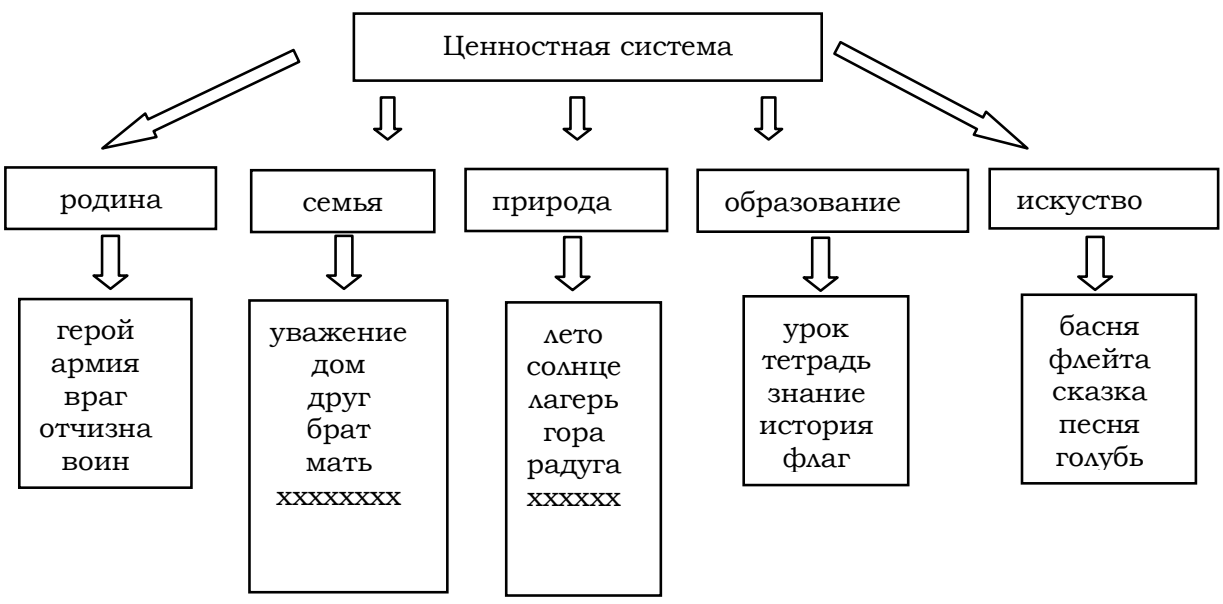

Рис. 3. Слова-стимулы, предложенные ученикам 3-его класса

После завершения групповой работы бым проведен повторный САЭ по тем же словам-стимулам и по формуле (1) были определены новые рейтинговые факторы, по которым были сформированы новые группы для последующих групповых работ (табц. 2). Этот цикл можно повторить несколько раз.

Таблица 2

Результаты 1-ого и 2-ого САЭ и структура групп

\begin{tabular}{|c|c|c|c|c|c|c|c|c|c|c|c|c|}
\hline \multirow{3}{*}{ 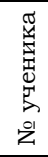 } & \multicolumn{6}{|c|}{$\begin{array}{c}\text { Оценки откликов 1-ого САЭ, } \\
\text { коэффицциенты рейтинга } \\
\text { (максимальное значение) }\end{array}$} & \multicolumn{6}{|c|}{$\begin{array}{c}\text { Оценки откликов 2-ого САЭ, } \\
\text { коэфффициенты рейтинга } \\
\text { (максимальное значение) }\end{array}$} \\
\hline & \multicolumn{2}{|c|}{$3 \mathrm{a}$} & \multicolumn{2}{|c|}{36} & \multicolumn{2}{|c|}{$3 \Gamma$} & \multicolumn{2}{|c|}{$3 a$} & \multicolumn{2}{|c|}{36} & \multicolumn{2}{|c|}{$3 r$} \\
\hline & 1 & 2 & 3 & 4 & 5 & 6 & 7 & 8 & 9 & 10 & 11 & 12 \\
\hline 1 & 18 & \multirow{3}{*}{$\begin{array}{l}0.23 \\
(0.38)\end{array}$} & 44 & \multirow{3}{*}{$\begin{array}{l}0.45 \\
(0.47)\end{array}$} & 17 & \multirow{5}{*}{$\begin{array}{c}0.2 \\
(0.9)\end{array}$} & 27 & \multirow{3}{*}{$\begin{array}{l}0.32 \\
(0.46)\end{array}$} & 55 & \multirow{3}{*}{$\begin{array}{c}0.56 \\
(0.6)\end{array}$} & 36 & \multirow{4}{*}{$\begin{array}{l}0.42 \\
(0.51)\end{array}$} \\
\hline 2 & 41 & & 49 & & 38 & & 52 & & 62 & & 55 & \\
\hline 3 & 56 & & 50 & & 44 & & 60 & & 64 & & 56 & \\
\hline 4 & 62 & \multirow{3}{*}{$\begin{array}{l}0.62 \\
(0.63)\end{array}$} & 54 & \multirow{4}{*}{$\begin{array}{l}0.54 \\
(0.57)\end{array}$} & 49 & & 65 & \multirow{3}{*}{$\begin{array}{l}0.66 \\
(0.67)\end{array}$} & 66 & \multirow{5}{*}{$\begin{array}{c}0.67 \\
(0.7)\end{array}$} & 58 & \\
\hline 5 & 64 & & 54 & & 49 & & 68 & & 67 & & 64 & \multirow{5}{*}{$\begin{array}{l}0.65 \\
(0.68)\end{array}$} \\
\hline 6 & 65 & & 61 & & 53 & \multirow{4}{*}{$\begin{array}{l}0.54 \\
(0.57)\end{array}$} & 68 & & 71 & & 66 & \\
\hline 7 & 66 & \multirow{4}{*}{$\begin{array}{l}0.67 \\
(0.69)\end{array}$} & 61 & & 57 & & 70 & & 72 & & 69 & \\
\hline 8 & 68 & & 64 & & 57 & & 71 & $\begin{array}{l}0.7 \\
(0.71)\end{array}$ & 75 & & 69 & \\
\hline 9 & 70 & & 65 & 0.64 & 60 & & 73 & & 78 & & 73 & \\
\hline 10 & 73 & & 65 & $(0.65)$ & 63 & $\begin{array}{c}0.6 \\
(0.6)\end{array}$ & 76 & $\begin{array}{l}0.76 \\
(0.76)\end{array}$ & 79 & $(0.79)$ & 76 & $\begin{array}{l}0.76 \\
(0.77)\end{array}$ \\
\hline
\end{tabular}


Окончание таблицы 1

\begin{tabular}{|c|c|c|c|c|c|c|c|c|c|c|c|c|}
\hline \multirow{3}{*}{ 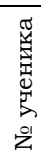 } & \multicolumn{6}{|c|}{$\begin{array}{c}\text { Оценки откликов 1-ого САЭ, } \\
\text { коэффициенты рейтинга } \\
\text { (максимальное значение) }\end{array}$} & \multicolumn{6}{|c|}{$\begin{array}{c}\text { Оценки откликов 2-ого САЭ, } \\
\text { коэффициенты рейтинга } \\
\text { (максимальное значение) }\end{array}$} \\
\hline & \multicolumn{2}{|c|}{$3 a$} & \multicolumn{2}{|c|}{3 б } & \multicolumn{2}{|c|}{$3 \Gamma$} & \multicolumn{2}{|c|}{$3 a$} & \multicolumn{2}{|c|}{3 б } & \multicolumn{2}{|c|}{$3 \Gamma$} \\
\hline & 1 & 2 & 3 & 4 & 5 & 6 & 7 & 8 & 9 & 10 & 11 & 12 \\
\hline 11 & 76 & \multirow{5}{*}{$\begin{array}{l}0.75 \\
(0.78)\end{array}$} & 69 & \multirow{4}{*}{$\begin{array}{l}0.70 \\
(0.71)\end{array}$} & 63 & & 76 & & 79 & & 78 & \\
\hline 12 & 76 & & 71 & & 64 & & 77 & & 79 & & 78 & \\
\hline 13 & 76 & & 72 & & 64 & & 78 & \multirow{3}{*}{$\begin{array}{l}0.78 \\
(0.8)\end{array}$} & 84 & \multirow{3}{*}{$\begin{array}{l}0.84 \\
(0.84)\end{array}$} & 80 & \multirow{4}{*}{$\begin{array}{l}0.80 \\
(0.81\end{array}$} \\
\hline 14 & 78 & & 72 & & 65 & & 80 & & 84 & & 80 & \\
\hline 15 & 86 & & 73 & \multirow{4}{*}{$\begin{array}{l}0.74 \\
(0.75)\end{array}$} & 67 & \multirow{3}{*}{$\begin{array}{l}0.67 \\
(0.67)\end{array}$} & 86 & & 84 & & 80 & \\
\hline 16 & & & 75 & & 67 & & & & 85 & \multirow{6}{*}{$\begin{array}{l}0.85 \\
(0.86)\end{array}$} & 82 & \\
\hline 17 & & & 75 & & 68 & & & & 85 & & 83 & \multirow{4}{*}{$\begin{array}{r}0.83 \\
(0.82\end{array}$} \\
\hline 18 & & & 76 & & 69 & \multirow{4}{*}{$\begin{array}{l}0.69 \\
(0.7)\end{array}$} & & & 85 & & 83 & \\
\hline 19 & & & 77 & \multirow{3}{*}{$\begin{array}{l}0.77 \\
(0.79)\end{array}$} & 69 & & & & 85 & & 84 & \\
\hline 20 & & & 78 & & 72 & & & & 86 & & 84 & \\
\hline 21 & & & 81 & & 72 & & & & 89 & & 86 & \multirow{5}{*}{$\begin{array}{l}0.86 \\
(0.87)\end{array}$} \\
\hline 22 & & & & & 74 & \multirow{4}{*}{$\begin{array}{l}0.75 \\
(0.76)\end{array}$} & & & & & 86 & \\
\hline 23 & & & & & 76 & & & & & & 87 & \\
\hline 24 & & & & & 76 & & & & & & 87 & \\
\hline 25 & & & & & 76 & & & & & & 88 & \\
\hline
\end{tabular}

Сравнение рейтинговых коэффициентов, определенных по результатам первого и второго САЭ (табл. 2), показывает, что рейтинги групп каждого класса увеличились, приближаясь к своему максимальному значению. Это, с одной стороны, свидетельствует об эффективности методик проведенных групповых работ, с другой стороны показывает, что уровени ЧЯ как каждого отдемьного ученика, так и групп учеников имеют поможительную динамику роста.

Таким образом, полученные результаты позволяют делать следующее залючение: метод САЭ является эффективным инструментом для опредемения уровня ЧЯ респондентов, а предложенная комплексная методика развития ЧЯ обеспечивает устойчивую динамику роста уровня ЧЯ каждого студента (ученика), развивает навыки педагогикоисследовательской работы студентов педагогических вузов и стимулирует их применение в живом педагогическом процессе.

References

[1] Kainz F. Psychologie der Sprache. Stuttgart, 1941. Bd. 1,3. Aufl., 1965. P. 186.

[2] Гохлернер М.М., Ейгер Г.В. Психологический механизм чувства языка. Вопросы психомогии, 1983. №4. С. 137.

[3] Васимьева В.Ф. "Языковое мышиение" и "внутренние законы" языка. Язык, сознание, коммуникация: сб. статей. М.: МАКС прес, 2009. № 38. С. 89.

[4] Божович Е.Д. Учителю о языковой компетенции ребенка. Психомогопедагогические аспекты языкового образования. М.: МПСИ, 2002. 278 с.

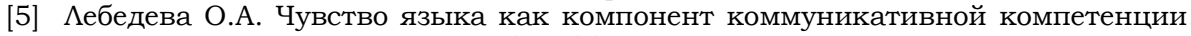
Вестник ТГУ, 2008. № 311. С.153-155.

[6] Thumb A., Marbe K., Experimentelle Untersuchungenüber die psychologishen Grundlagen der sprachlichen Analogiebildung. Leipzig, 1901. P. 108.

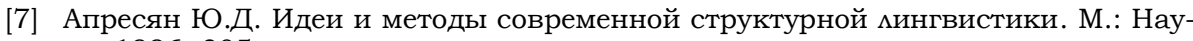
ка, 1996. 305 c.

[8] Bousfield W.A., G.A., Berkowitz H. Partial responses identities in associative clustering. J. of general psychology, 1960. V. 63. P. 233-238.

[9] Deese J. The structure of associations in language and thought.Baltimore, J. Hopkins press, 1966. P. 216. 